\title{
Prevalence of goitre and hypothyroidism in Southern Tanzania: effect of iodised oil on thyroid hormone deficiency*
}

\author{
W WÄCHTER ${ }^{1}$, M MVUNGI, ${ }^{2}$ A KÖNIG ${ }^{3}$ C R PICKARDT, ${ }^{3}$ AND P C SCRIBA 4 \\ From 6296 Mengerskirchen; ${ }^{1}$ Lutheran Hospital, ${ }^{2}$ Ilembula via Iringa, Tanzania; Medizinische Klinik \\ Innenstadt der Universität München, ${ }^{3}$ Ziemssenstrasse 1, D-8000 München 2, West Germany; Klinik für \\ Innere Medizin der Universität, ${ }^{4}$ Ratzeburger Allee 160, D-2400 Lübeck 1, West Germany
}

SUMmaRY In the Southern Highlands of Tanzania the prevalence of endemic goitre due to iodine deficiency is in the range of $90 \%$ and hypothyroidism in the range of $50 \%$ of schoolchildren. The present study confirms these data and documents the beneficial effect of Lipiodol injections on thyroid function in children around the age of puberty compared with untreated children from the same villages. On the other hand, a decrease in the prevalence of goitre could not be shown. A beneficial effect is shown for infants of mothers who received iodine during pregnancy. It seems that this form of supplementation is sufficient for breast fed children for more than three years, even when a second child has been delivered in the meantime. In contrast, older siblings of these babies may become hypothyroid when breast feeding is stopped. The determination of thyroid autoantibodies in iodine treated and untreated children and in young adults showed no increasing prevalence of positive findings thus excluding iodine induced chronic thyroiditis at least in the young target population.

The southern highlands of Tanzania are known to be an area with a high prevalence of endemic goitre ${ }^{12}$ and hypothyroidism ${ }^{2}$ due to iodine deficiency. Therefore, in 1979, privately initiated iodine supplementation was undertaken regionally in order to motivate the local medical establishment into continuing this programme.

A reinvestigation was performed in 1982 in order to

1 reestablish the persistence of a high prevalence of goitre in untreated schoolchildren;

2 make a comparison between treated and untreated children from the same villages, which differed only with respect to their age;

3 study the beneficial effect of iodised oil, given to pregnant women, by investigation of mothers and infants three years later; and

4 exclude harmful thyroiditis ${ }^{34}$ induced by iodised oil by investigation of thyroid autoantibodies in untreated and treated children and adults.

The data are presented to draw the attention of the local authorities to the iodine deficiency problems.

*Supported by Berliner Missionswerk, Division for World Mission, Berlin, West Germany

\section{Methods}

Thyroid enlargement was determined by palpation and classified according to the WHO recommendations. ${ }^{56}$ Thyroid palpations were performed by three different investigators.

Thyroid hormone levels, thyroxine binding globulin (TBG) and serum TSH levels were determined by radioimmunoassay, as described elsewhere. $^{7-9}$ Thyroid antibodies were determined using commercial test systems (Fa Welcome, Burgwedel, FRG). Blood spot TSH from filter paper was determined as previously described. ${ }^{2}$ Blood samples were drawn from a cubital vein. Samples were centrifuged, and serum was stored at $4^{\circ} \mathrm{C}$ for up to 10 days and thereafter frozen at $-20^{\circ} \mathrm{C}$ until determinations were performed. Blood samples for blood spot TSH analysis were taken from fingerprick from 30 infants. Filter papers were thoroughly dried and stored in the same way as serum samples.

Normal ranges for healthy controls from Munich were: thyroxine $\left(\mathrm{T}_{4}\right) \quad 4 \cdot 5-10 \cdot 0 \mu \mathrm{g} / \mathrm{dl}$; thyroxine binding globulin (TBG) $1.6-2.8 \mathrm{mg} / \mathrm{dl} ; \mathrm{T}_{4} / \mathrm{TBG}$ ratio $1 \cdot 8-5 \cdot 7$ (arbitrary units); triiodothyronine $\left(\mathrm{T}_{3}\right)$ 80-160 ng/dl; thyrotropin (TSH) 0-2.1 mU/1. 
The TSH radioimmunoassay was performed using a low labelled ${ }^{125}$ I-TSH tracer and a prolonged incubation time. TSH standards were diluted in human serum from volunteers during $T_{3}$ suppression $(100 \mu \mathrm{g} / \mathrm{d})$. The lower limit of detection is $0 \cdot 4 \mathrm{mU} / \mathrm{l}^{7}$; the normal basal level in the Bavarian goitre region is below $2 \cdot 1 \mathrm{mU} / \mathrm{l}$; thus serum levels in the range $2 \cdot 2-5 \cdot 0 \mathrm{mU} / 1$ were assumed to be borderline, whereas serum levels over $5 \mathrm{mU} / \mathrm{l}$ are clearly indicative of hypothyroidism.

In euthyroid children more than 10 days old and in adults, blood spot TSH (lower limit of detection $12 \mathrm{mU} / \mathrm{l}$ ) is undetectable. In a previous study ${ }^{2}$ we showed that blood spot TSH levels below $12 \mathrm{mU} / 1$ do not necessarily exclude moderate or mild hypothyroidism, because of a loss of TSH activity on the filter paper, presumably due to environmental humidity. In this study the transport time was less than two weeks and the filter papers were kept in a cool box during the time of sampling.

\section{Study population}

\section{G ROU P I}

Five hundred and sixty children from seven different villages who had never received iodine prophylaxis ${ }^{2}$ were investigated for thyroid enlargement and thyroid function.

\section{GROUP III}

For comparison, 124 children from three different villages who had received iodine supplementation (1 ml Lipiodol ${ }^{\mathrm{R}}$, Byck-Gulden Federal Republic Germany, im, containing $480 \mathrm{mg}$ iodine bound to ethyl-ester of oleum papaveris) three years previously, were reinvestigated.

\section{G ROU P II}

This special group was compared with 134 children of younger age, from the same three villages who had not yet received iodine.

The age was requested from the children but this information cannot be relied on, because the date of birth is not documented in the rural areas of Tanzania. It is obviously doubtful whether children attending primary school are more than 16 years of age in groups I and III. Therefore, those who gave an age of 17-47 years $(n=30)$ were not eliminated.

In addition, 25 young women, who had received iodised oil during pregnancy in 1979, their babies born in $1979 / 80(n=25)$, and five younger babies born in 1981/82 were investigated. TSH levels of the children were determined by the filter paper method.

Thyroid autoantibodies were investigated in 138 untreated children and adults as well as in 174 treated children and adults to exclude a possible increase in immunological reactions after a high dose of lipid bound iodine.

Wilcoxon Rank test was used for statistical analysis.

\section{Results}

CHILDREN WITHOUT IODINE PROPHYLAXIS (GROUP I)

A total of 560 schoolchildren, 6-19 years of age, were investigated before iodine supplementation.
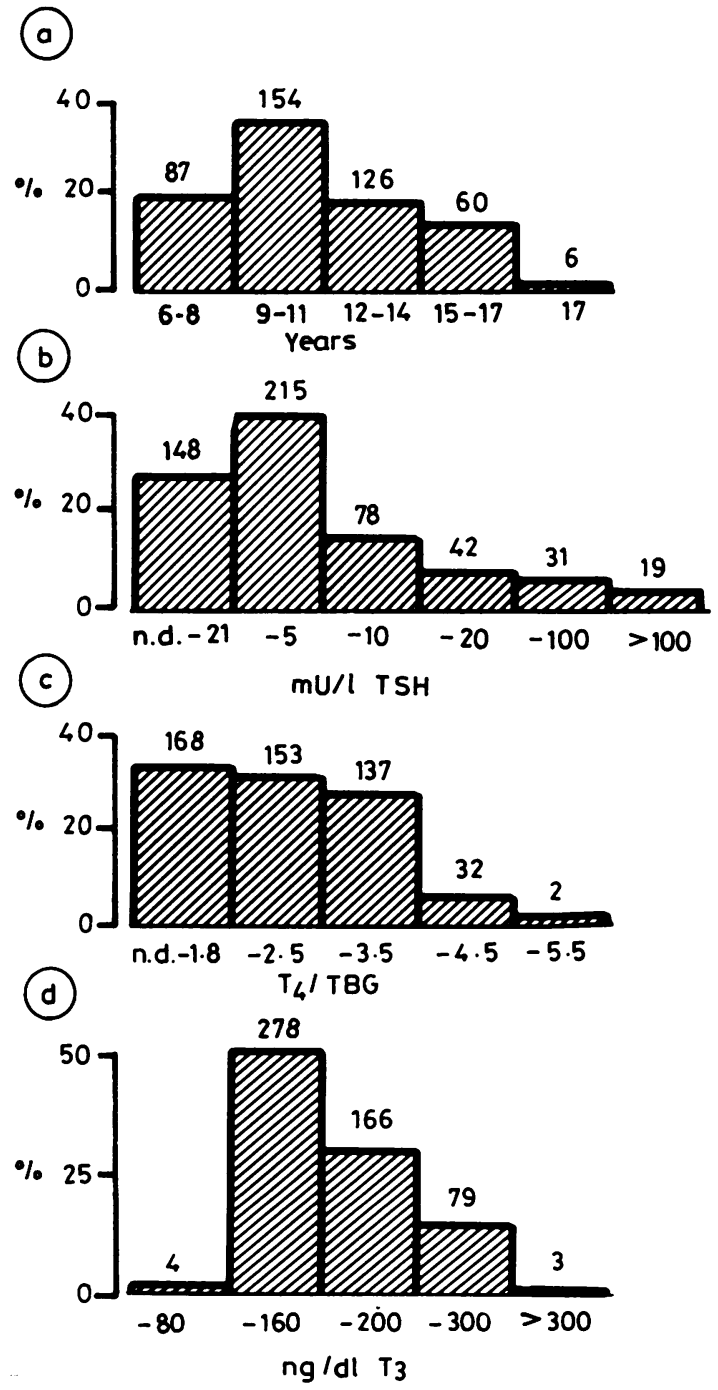

Fig 1 Distribution of age (A), TSH levels (B), $T_{4} / T B G$ ratio $(C)$, and $T_{3}$ levels $(D)$ in 560 schoolchildren from different villages in Uwanje. As indicated by the different numbers for the various parameters, data are not complete for technical reasons. 
The distribution of age, TSH levels, $\mathrm{T}_{4} / \mathrm{TBG}$ ratio, and $T_{3}$ levels is given in figure 1.

The $T_{4} /$ TBG ratio was normal in only $67 \%$ (table 1) and normal TSH levels were found in only $31 \%$ of these children; $41 \%$ had moderately elevated TSH levels in the range $2 \cdot 2-5 \cdot 0 \mathrm{mU} / \mathrm{l}$, whereas $28 \%$ of the TSH levels were in the range $5 \cdot 1-745 \mathrm{mU} / \mathrm{l}$, indicating frank hypothyroidism. There was a significant correlation between the $T_{4} / \mathrm{TBG}$ ratios and basal TSH levels $(p<0 \cdot 01)$. No correlation was shown for $\mathrm{T}_{3}$ and TSH levels.

The overall prevalence of goitre was $90 \%$ in 512 children of group I. For the difference in numbers of children in figs 1 and 2 see fig $1 ; 75 \%$ of these children (fig 2) had goitre grades I and II. Goitre grade III increased significantly with age $(p<0 \cdot 01)$.

COMPARISON OF CHILDREN WITH AND WITHOUT PREVIOUS IODINE PROPHYLAXIS

The data for 124 children from three different villages, who had received iodised oil injections three years previously (group III), were compared with those of 134 children without iodine supplementation (group II) from the same villages.

According to the selection, the children forming group III were significantly older than those in group II (fig 3), because only the younger ones, not yet attending school in 1979, had not received iodised oil injections. Thyroid function in group III was significantly different in all parameters tested $(\mathrm{p}<0 \cdot 01$, table 2$)$.

The most striking difference was found for the TSH levels. Mean TSH level was only slightly elevated in the iodine treated group but clearly elevated with a wide range of variation in the untreated group. Out of 134 untreated children, 64 (48\%) had basal TSH levels of $5 \mathrm{mU} / \mathrm{l}$ and more, whereas in only 8 out of $123(6.5 \%)$ treated children was TSH above $5 \mathrm{mU} / \mathrm{l}$.

As shown in table 1 (middle and right part) $45 \cdot 5 \%$ of children without previous iodine supplementation in group II exhibited thyroxine deficiency. In group II

Table 1 Comparison of thyroid function of children from the same villages without (group II) and with (group III) iodine prophylaxis

\begin{tabular}{|c|c|c|c|c|c|c|}
\hline \multirow[b]{2}{*}{ TSH } & \multicolumn{2}{|l|}{ Group I } & \multicolumn{2}{|l|}{ Group II } & \multicolumn{2}{|c|}{ Group III } \\
\hline & $\begin{array}{l}T_{\triangleleft} / T B G \\
<1.8\end{array}$ & $\begin{array}{l}\text { ratio } \\
>1 \cdot 8\end{array}$ & $\begin{array}{l}T_{4} / \mathrm{TBG} \\
<1 \cdot 8\end{array}$ & $\begin{array}{l}\text { ratio } \\
>1 \cdot 8\end{array}$ & $\begin{array}{l}\mathrm{T}_{4} / \mathrm{TBG} \\
<1.8\end{array}$ & $\begin{array}{l}\text { ratio } \\
>1.8\end{array}$ \\
\hline \multirow[t]{2}{*}{$\begin{array}{l}\leqslant 2 \cdot 1 \\
2 \cdot 2-5 \cdot 0 \\
>5 \cdot 0\end{array}$} & $\begin{array}{r}4 \cdot 7 \\
10 \cdot 6 \\
17 \cdot 9\end{array}$ & $\begin{array}{l}26 \cdot 1 \\
30 \cdot 5 \\
10 \cdot 4\end{array}$ & $\begin{array}{r}3.0 \\
9.0 \\
33.6\end{array}$ & $\begin{array}{l}15 \cdot 7 \\
24 \cdot 6 \\
14 \cdot 2\end{array}$ & $\begin{array}{l}1.6 \\
0.8 \\
1.6\end{array}$ & $\begin{array}{r}50.8 \\
39.5 \\
5.6\end{array}$ \\
\hline & 33.0 & $67 \cdot 0$ & $45 \cdot 5$ & $54 \cdot 5$ & $4 \cdot 0$ & 96.0 \\
\hline
\end{tabular}

Group I. 512 children without iodine prophylaxis

Group II. 134 children without iodine prophylaxis from three selected villages. Group III. 124 children from the same villages three years after $1 \mathrm{ml}$ iodised oil im.
Table 2 Relative distribution of normal, borderline and clearly elevated TSH levels in relation to decreased and normal $T_{4} /$ TBG ratio

\begin{tabular}{llrlll}
\hline & \multicolumn{3}{l}{ Group II } & & Group III \\
\cline { 2 - 3 } \cline { 5 - 6 } & $n$ & & $n$ \\
\hline Age (yr) & 133 & $9 \cdot 4 \pm 1 \cdot 3$ & & 111 & $13 \cdot 3 \pm 1 \cdot 8$ \\
T3 (ng/dl) & 132 & $185 \pm 52$ & & 123 & $160 \pm 32$ \\
Ta/TBG & 129 & $2 \cdot 1 \pm 1 \cdot 0$ & & 124 & $3 \cdot 0 \pm 0 \cdot 9$ \\
TSH (mU/l) & 134 & $20 \cdot 6 \pm 70 \cdot 6$ & & 123 & $2 \cdot 6 \pm 2 \cdot 4$ \\
\hline
\end{tabular}
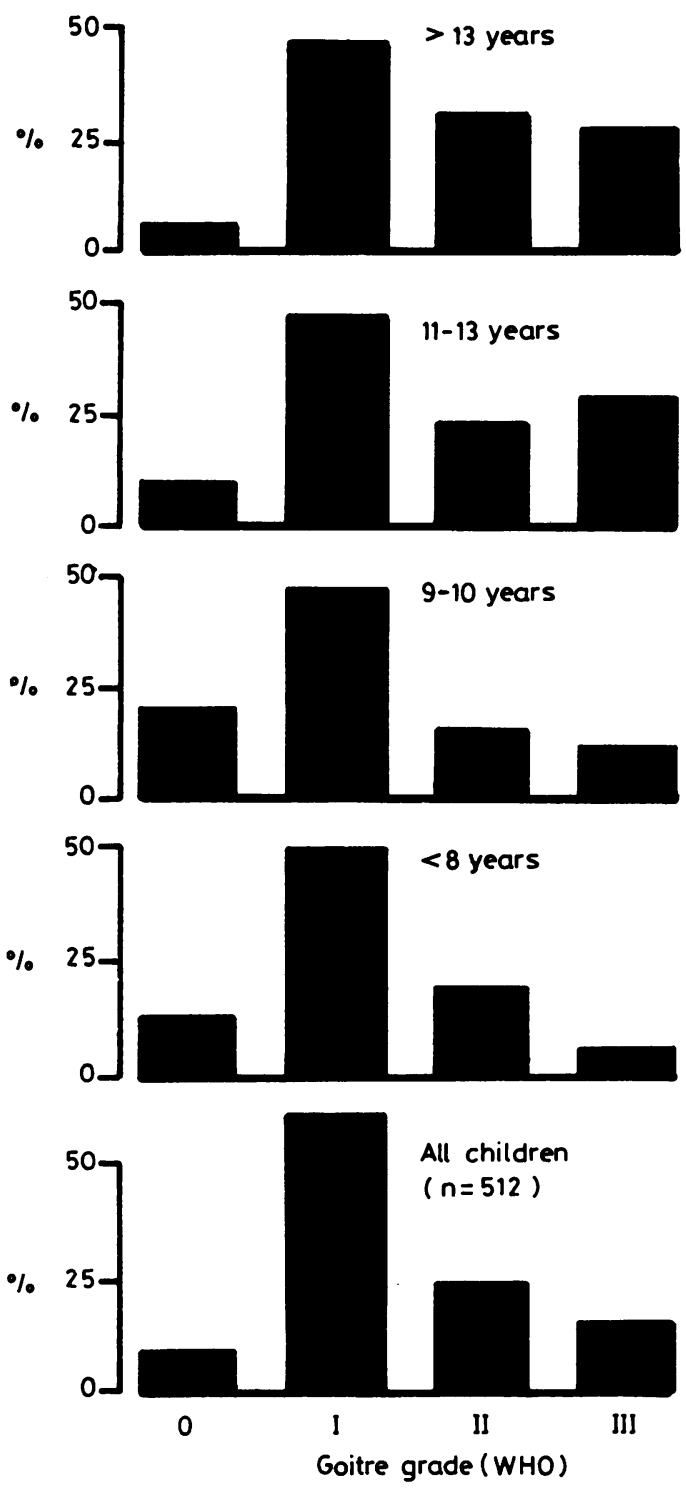

Fig 2 Distribution of goitres in 512 children without iodine prophylaxis. 


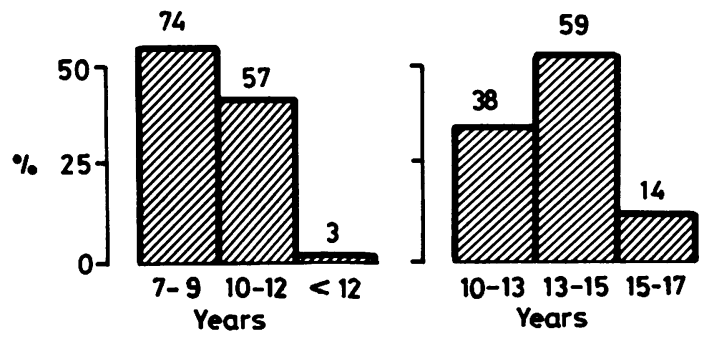

Fig 3 Age distribution of children from the same villages without (left) and with (right) iodine prophylaxis.

only $15.6 \%$ were euthyroid in terms of both normal $\mathrm{T}_{4} / \mathrm{TBG}$ ratio and normal TSH level. In contrast, only $4 \%$ of children who had received iodised oil 3 years previously, showed a decreased $\mathrm{T}_{4} / \mathrm{TBG}$ ratio. In this group, $50.8 \%$ were euthyroid in terms of normal $\mathrm{T}_{4} / \mathrm{TBG}$ ratio and $\mathrm{TSH}$ levels.

Comparison of the different grades of goitre did not reveal significant differences between groups II and III.

REINVESTIGATION OF MOTHERS RECEIVING IO DINE DURING PREG NANCY A N D INVESTIGATION OF THEIR CHILDREN

In one village, 25 mothers who had received iodine in 1979 during pregnancy and 25 children born in
$1979 / 80$ as well as five children born in 1981/82 were reinvestigated. All mothers had serum TSH levels below $2 \cdot 1 \mathrm{mU} / \mathrm{l}$. The TSH levels as measured by the filter paper method were elevated in 7 out of 25 older babies (28\%) (fig. 4) but in none of the younger babies. All of the latter were breast fed.

THYROID AUTOANTIBODIES IN UNTREATED AND IODINE TREATED CHILDREN AND ADULTS

As shown in table 3 , microsomal antibodies were undetectable in 311 out of 312 treated and untreated subjects. One out of 156 treated children from group I had a low positive titre. Thyroglobulin antibodies were borderline positive in 2 out of 126 untreated and in another 2 out of 154 iodine treated children.

\section{Discussion}

The investigation of schoolchildren before iodine supplementation again demonstrates the high prevalence of endemic goitre in this area. ${ }^{12}$ The high prevalence of overt and borderline hypothyroidism among the schoolchildren without supplementation was confirmed. Despite the fact that up to now no concise information on the mental and somatic handicaps of these children is available, there is no doubt that the degree of biochemically confirmed hypothyroidism alone indicates the need for an
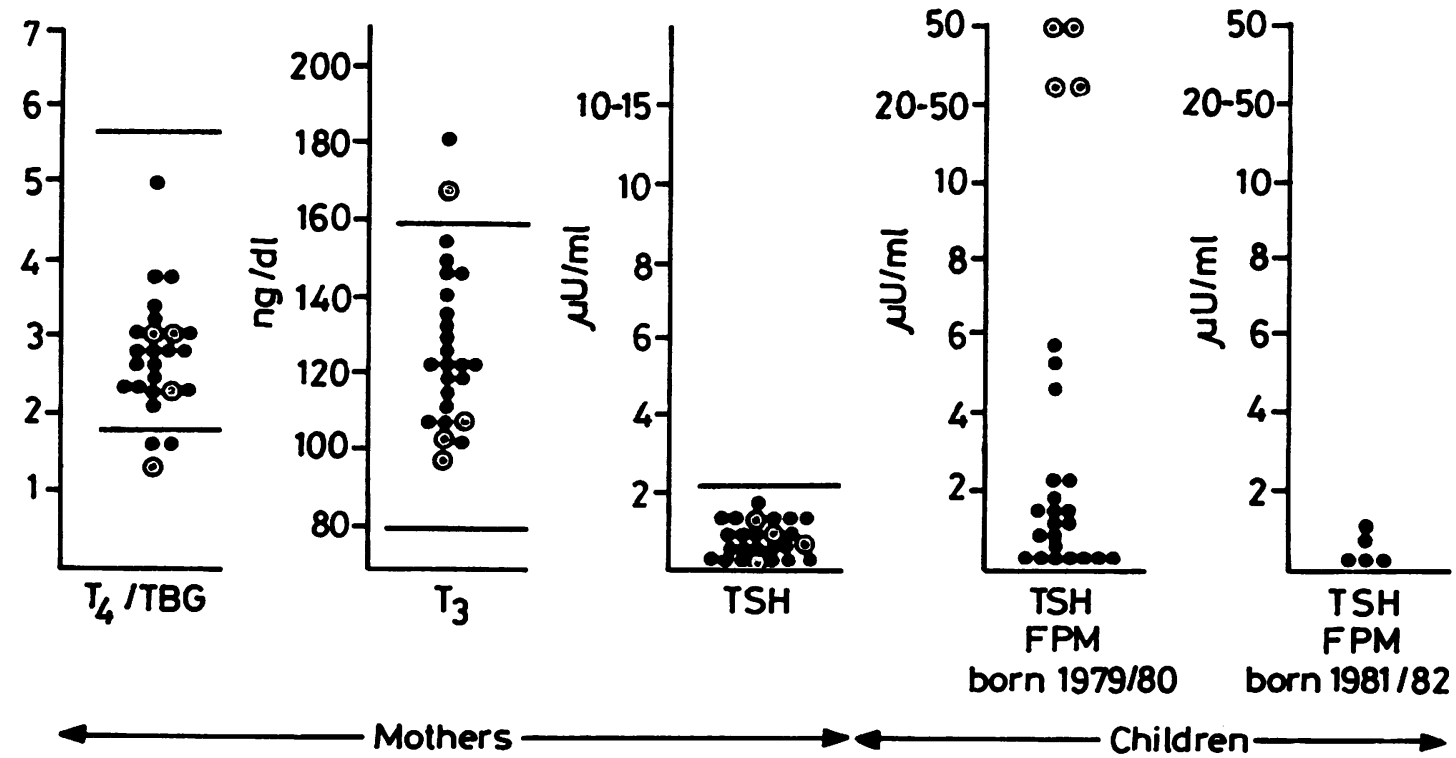

Mothers

Fig $4 \mathrm{~T}_{4} / T B G$ ratio, $T_{3}$ and TSH levels in 25 young females, who received iodine prophylaxis during pregnancy three years previously and TSH-levels of the children delivered shortly after iodine injection as well as TSH levels of children born 2-3 years after iodine injection. For identification of individual thyroid hormone levels, symbols of children with TSH levels above $20 \mathrm{mU} / \mathrm{l}$ are ringed. 
Table 3 Thyroid autoantibodies in untreated and in Lipiodol treated children and adults

\begin{tabular}{|c|c|c|c|c|c|}
\hline & \multirow[b]{2}{*}{$n$} & \multicolumn{2}{|c|}{$M a b$} & \multicolumn{2}{|c|}{ Tgab } \\
\hline & & Pos & Neg & Pos & Neg \\
\hline $\begin{array}{l}\text { Untreated children } \\
\text { Untreated adults with goitre } \\
\text { Treated children } \\
\text { Treated women }\end{array}$ & $\begin{array}{r}128 \\
10 \\
156 \\
18\end{array}$ & $\begin{array}{l}\mathbf{0} \\
0 \\
1 \\
0\end{array}$ & $\begin{array}{r}128 \\
10 \\
155 \\
18\end{array}$ & $\begin{array}{l}2 \\
0 \\
2 \\
0\end{array}$ & $\begin{array}{r}126 \\
10 \\
154 \\
18\end{array}$ \\
\hline Totals & 312 & 1 & 311 & 4 & 308 \\
\hline
\end{tabular}

effective iodine supplementation programme in this area.

The comparison of untreated and iodine treated children from the same villages shows the beneficial long-term effect on thyroid function of $1 \mathrm{ml}$ Lipiodol im in terms of lower TSH levels and higher $\mathrm{T}_{4} / \mathrm{TBG}$ ratios in the treated group. It could be shown that $96 \%$ of the treated children had normal $\mathrm{T}_{4} / \mathrm{TBG}$ ratios. However, investigation of the more sensitive parameter of thyroid hormone deficiency, ie, TSH determination, shows that only $50 \%$ of these children were fully euthyroid when compared with basal TSH levels of normal controls from the mild iodine deficiency area in Southern Germany. ${ }^{7}$ This finding is to be expected because urinary iodine excretion decreases exponentially with a half-life of 5.6 months after injection of iodised oil. ${ }^{5}$

Moreover comparison reveals that this supplementation did not result in a sufficient decrease of thyroid enlargement. However, it cannot be excluded that the goitres of these children had exhibited a transient decrease during optimal iodine effect as described in other regions. ${ }^{5}$

For these two reasons, the interval between iodine injections should probably be shorter than three years, at least for children in puberty and adolescence when euthyroid function, in terms of both normal $\mathrm{T}_{4} / \mathrm{TBG}$ ratio and normal serum $\mathrm{TSH}$ level and a nearly normal thyroid volume, is the aim of such a supplementation programme.

In a previous study, ${ }^{2}$ we showed that blood spot TSH levels below $12 \mathrm{mU} / \mathrm{l}$ do not necessarily exclude moderate or mild hypothyroidism, because TSH activity is partly lost on the filter paper, but frank hypothyroidism may not be overlooked by using this kind of TSH measurement. Therefore, we judge that filter paper TSH from a finger prick of the 30 babies gives a rough insight into the protective effect of $1 \mathrm{ml}$ iodised oil for mothers and newborns, when investigated three years after the mothers had received iodised oil during pregnancy. All of the women had normal TSH levels three years after the injection, whether they had given birth to a second child in the meantime or not. Among the older babies of these women, $28 \%$ were found to be hypothyroid after stopping breast feeding, whereas none of the second children had elevated TSH levels. All of the latter were still breastfed. Thus, maternal milk seems to be a sufficient source of iodine for these children since it had been shown that there is a linear relation between iodine content in the milk and maternal iodine excretion, at least in borderline iodine deficiency. ${ }^{10}$ This finding indicates that iodine prophylaxis should be given to children as soon as breastfeeding is stopped.

In our study, there is no suspicion that intramuscular injection of iodised oil increases the rate of chronic thyroiditis in children and young adults, because thyroid antibodies did not increase compared with the untreated study population. This is in contrast to the observation of Boukis et al, ${ }^{3}$ who found an increased rate of thyroglobulin and microsomal antibodies, up to $42 \cdot 8 \%$, three and six months after oil injection in their study population 19-60 years of age. Our finding is also in contrast to the observation in regions with an effective prophylaxis programme with iodised salt. ${ }^{4}$ Although we cannot exclude a transient increase in thyroid antibodies in our sample, we can conclude from our data that this rough form of iodine prophylaxis does not induce harmful chronic thyroiditis in the young population, which is the main target for prophylaxis programmes.

We thank the Berliner Mission for supporting Dr M Mvungi and for donating the iodised oil (Lipiodol). We also thank Dr Kadete and his staff, of the Ilembula Lutheran Hospital who took part in the reinvestigation programme; the technical staff of the endocrine laboratories of the Medizinische Klinik Innenstadt der Universität München for determination of the thyroid function parameters; and Mrs R Thomeier for her thorough preparation of the manuscript.

\section{References}

${ }^{1}$ Latham MC. The aetiology, prophylaxis and treatment of endemic goitre in Ukinga, Tanzania. East A frican Medical J 1965; 42: 489-501.

${ }^{2}$ Wächter W, Mvungi MG, Triebel E, et al. Iodine deficiency, hypothyroidism and endemic goitre in Southern Tanzania. A survey showing the positive effects of iodizhed oil injections by TSH determination in dried blood spots. J Epidemiol Community Health, 1985,39 (3) 263-270.

${ }^{3}$ Boukis MA, Koutras DA, Souvatzoglou A, et al. Thyroid hormone and immunological studies in endemic goiter.J Clin Endocrinol Metab 1983; 57: 859-62.

${ }^{4}$ Harach HR, Escalante DA, Onativia A, et al. Thyroid carcinoma and thyroiditis in an endemic goitre region before and after iodine prophylaxis. Acta Endocrinol 1985; 108: 55-60. 
${ }^{5}$ Hetzel BS, Thilly CH, Fierro-Benitez R, et al. Iodized oil in the prevention of endemic goiter and cretinism. In: Endemic goiter and cretinism-iodine nutrition in health and disease. JB Stanbury, BS Hetzel, eds. New York, Chichester, Brisbane, Toronto: John Wiley and Sons Inc. 1980; 513-32.

${ }^{6}$ Perez C, Scrimshaw NS, Munoz JA. Technique of endemic goitre surveys. In: Endemic goitre. Monograph series no. 44 Geneva: World Health Organization, $1960 ; 369-84$.

${ }^{7}$ Erhardt F, Marschner I, Pickardt CR, et al. Verbesserung und Qualitätskontrolle der radioimmunologischen Thyrotropin-Bestimmung. J Clin Chem Clin Biochem 1973; 11: 381-7.
${ }^{8}$ Gärtner R, Kewenig M, Horn K, et al. A new principle of thyroxine ( $\left.\mathrm{T}_{4}\right)$ and triiodothyronine ( $\left.\mathrm{T}_{3}\right)$ radioimmunoassay in unextracted serum using antisera with binding optima at extreme $\mathrm{pH}$ ranges. J Clin Chem Clin Biochem, 1980; 18: 571-7.

${ }^{y}$ Horn K, Kubiczek Th, Pickardt CR, et al. Thyroxin-bindendes Globulin (TBG): Präparation, radioimmunologische Bestimmung und klinisch-diagnostische Bedeutung. Klin Wschr 1977; 55: 881-94.

${ }^{10}$ Heidemann PH. Die Struma im Neugeborenen- und Kindesalter. Stuttgart-New York: Thieme, 1984.

${ }^{11}$ Dunn JT, Medeiros-Neto GA. Endemic goiter and cretinism: Continuing threats to world health. Pan American Health Organization Scientific Publication no 292, 1975. 